\title{
Prophylactic Use of Non-invasive Ventilation After Abdominal and Thoracic Surgery
}

\author{
Non-invazif Ventilasyonun Abdominal ve Torasik Cerrahi Sonrası Profilaktik Kullanımı
}

\author{
Ayșe Nur Yeksan', Cafer Mutlu Sarıkaș', Ürfettin Hüseyinoğlu', Sadık Avșar² \\ ${ }^{1}$ Department of Anaesthesiology and Reanimation, Kafkas University School of Medicine, Kars, Turkey; ${ }^{2}$ Department of Chest Diseases, \\ Kafkas University School of Medicine, Kars, Turkey
}

\begin{abstract}
All types of surgeries inevitably cause some sort of respiratory alterations. Postoperative pulmonary complications increase hospital stay, morbidity and mortality and are still significant problems in clinical practice. Nowadays, non-invasive ventilation is in common use and one of its uses is to prevent postoperative pulmonary complications. Thoracic and abdominal surgeries have high risks for pulmonary complications. Thus, we aimed to present a systematic review to analyze the results of prophylactic non-invasive ventilation use after abdominal and thoracic surgeries.
\end{abstract}

Key words: abdomen; non-invasive ventilation; postoperative complications; pulmonary atelectasis; surgery; thoracic surgery

\section{ÖZET}

Tüm cerrahi girișimler kaçınılmaz olarak bazı solunumsal değișikliklere sebep olur. Postoperatif akciğer komplikasyonları hastanede kalım süresi, mortalite ve morbiditeyi arttırırlar ve hala önemli klinik pratik sorunlardır. Bugünlerde, non-invazif ventilasyon kullanımı sıktır ve bir kullanımı da postoperatif akciğer komplikasyonları önlemektir. Toraks ve karın cerrahileri akciğer komplikasyonları açısından yüksek riske sahiptirler. Bunun için, karın ve toraks cerrahisinde koruyucu non-invazif ventilasyonun sonuçlarını incelemek için bir sistematik derleme sunmayı amaçladık.

Anahtar kelimeler: karın; non-invazif ventilasyon; postoperatif komplikasyonlar; pulmoner atelektazi; cerrahi; torasik cerrahi

\section{Introduction}

\section{Definition of Non-invasive Ventilation (NIV)}

In general terms, it is the way of giving mechanical respiratory support to the patient without the support of an artificial airway ${ }^{1}$. During NIV the protective mechanisms of upper airways are still active, and patients can speak, eat and clear their secretions by themselves during application.

The adventure of mechanical ventilation in clinical practice substantially had started with non-invasive method in 1900-1950s when so many polio pandemics had broken out. "Iron lungs" which covered whole body and generated "negative" pressure to assist ventilation saved lives although they were unpractical and unwieldy for routine use. Unfortunately, the mortality rate was still so high which necessitated discovering the positive pressure ventilation support via artificial airways in 1950s.

Initially, it was applied manually, however consequently in a short span of time first generation positive pressure ventilators were already fabricated. NIV or non-invasive positive pressure ventilation (NPPV, a synonym for NIV) using "positive" pressure became a major issue again in 1980 s when nasal continuous positive airway pressure (CPAP) was used in the treatment of sleep apnea. In 1990s, it was also used in the treatment of chronic obstructive lung disease, congestive heart failure and other conditions associated with respiratory insufficiency. Until now, NIV lost nothing from its popularity in clinical practice.
Yard. Doç. Dr. Ayşe Nur Yeksan, Kafkas Üniversitesi Tip Fakültesi, Anesteziyoloji ve Reanimasyon Anabilim Dalı 3600 Kars, Türkiye Tel.05353659095 Email.nur.yeksan@gmail.com

Gelis Tarihi: 07.08.2014 • Kabul Tarihi: 13.08.2014 


\section{Clinical Use of NIV}

NIV does not require the use of an artificially created airway like an intubation tube or tracheotomy cannula; however an interface connecting the patient to the supportive device is needed. A nasal, oro-nasal, full face or helmet mask can be used for this purpose. Any of the masks has its unique advantages and disadvantages, however obviously all require patient compliance during application. NIV support can be provided by a standard positive pressure ventilator, a specialized bilevel positive airway pressure (BiPAP) machine or a CPAP device ${ }^{2,3}$.

CPAP and BiPAP are two main NIV techniques. CPAP delivers a constant positive pressure during both inspiration and expiration, so there is not a separate inspiratory support; that means it improves oxygenation; however its efficacy on ventilation and work of breathing is limited ${ }^{4,5}$. On the other hand, BiPAP delivers two different pressure levels during inspiration and expiration. It helps both oxygenation and ventilation because it gives additional inspiratory support decreasing the work of breathing ${ }^{4,5}$.

Air leak is another important consideration during NIV application. Certainly, it depends on tightly fitting of the mask as well as patient's facial characteristics ${ }^{6}$. Air leaks lead to the loss of patient-ventilator synchronization which causes difficult and ineffective applications ${ }^{7}$. Ordinary intensive care ventilators are also used for NIV, however they don't provide a good synchrony if they don't have a leak compensation algorithm ${ }^{8}$. Besides, NIV ventilators have the ability of generating high flows and reducing patient-ventilator asynchrony, are improved over time and better than many intensive care ventilators for compensating air leaks?.

Although NIV is used in a wide variety of clinical situations in intensive care and emergency units, clinical trials and meta-analysis recommend its use in only four clinical situations with grade $1 \mathrm{~A}$ evidence ${ }^{10}$ :

1. Severe exacerbation of chronic obstructive lung disease.

2. Cardiac edema and respiratory failure in the absence of shock or acute coronary syndrome requiring acute coronary revascularization.

3. Facilitating extubation in chronic obstructive pulmonary disease (COPD) patients that cannot be weaned from the ventilator.

4. Acute respiratory failure in immune-compromised patients.
Obstructive sleep apnea is the most common breathing disorder and compromises upper airway muscle activity. Anesthetic drugs also compromise the same activity and the situation is worse postoperatively for patients having obstructive sleep apnea. NIV is a preferable option for these patients peri-operatively, even for a better wound healing because it provides a better oxygenation $^{11,12}$.

Asthma exacerbations, hypoxemic respiratory failure, extubation failure and post-operative respiratory failure are also among the clinical situations in which NIV is used. Ferrer et al. demonstrated superiority of NIV use in extubation failure patients compared to classical weaning protocol ${ }^{13}$.

Certainly, there are contraindications and complications of NIV application. Severe hypoxemia or acidemia, multi organ failure, anatomical face problems, severe agitation, copious secretion, uncontrolled vomiting, repetitive hemoptysis and hematemesis, upper airway obstruction, encephalopathy, impaired consciousness, apnea, cardiac arrest and patient's refusal of application are among contraindications. Thus, in most instances NIV use is contraindicated in the situations which we cannot control the airway safety and hemodynamic stability.

NIV is a quite safe and well tolerated technique for appropriate patients in proper conditions and can be used for short and long times. Adverse side effects usually are not so serious and they are mostly related to the mask, or flow and pressure levels of the ventilator. Some of the side effects related to mask use are discomfort, erythema on face, nasal ulceration and claustrophobia. Nasal congestion, ear pain, mouth/nose dryness, cornea irritation and gastric distension are among the complications related to flow and pressure. Besides; air leak, aspiration pneumonia, hypotension, pneumothorax are also among undesirable states. Clinicians must be careful about abdominal distension in patients having upper gastrointestinal anastomosis. Although it is never a contraindication for NIV use, it is always conflictive among anesthesiologists and surgeons.

\section{Postoperative Pulmonary Complications (PPC)}

All types of surgeries regardless of anesthesia choice (general or regional) cause some sort of respiratory alterations. PPC can simply be defined as any pulmonary abnormality observed in the postoperative period. This issue should not be underestimated during daily 
clinical practice because it increases the length of hospital stay, and the rates of morbidity and mortality ${ }^{14}$. Pneumonia, pneumothorax, pulmonary edema, pleurisy, aspiration, infection of airways, respiratory failure can be listed among these complications some of which rely on peri-operative atelectasis formation.

Atelectasis occurs in $90 \%$ of patients who are anesthetized $^{15}$; meaning that even a trouble-free anesthesia and surgery may not prevent atelectasis. Anesthesia leads to atelectasis by reducing functional residual capacity (FRC) which can be interpreted as resistance of lungs against collapse. Depression of the respiratory center by the used drugs, high $\mathrm{FiO}_{2}$, postoperative pain and direct muscle injury related to surgical incision are probably contributing factors ${ }^{16}$. Atelectasis and hypoventilation are most frequent reasons of early postoperative hypox$\mathrm{emia}^{17}$. Anesthetic drugs and neuromuscular blockers, although are easily reversible, have residual effects in the postoperative period, thus the risk of atelectasis also exists in the postoperative period ${ }^{5}$.

There are risk factors increasing the possibility of PPC and, thus, postoperative respiratory failure. Anesthetic factors along with surgical factors, type of surgery (particularly thoracic and abdominal surgeries), demographical factors (age, obesity, etc), and preexisting hypoxemia or lung disease increase the risk of PPC. Approximately $8-10 \%$ of patients need intubation and mechanical ventilation after abdominal surgery ${ }^{18}$. In a multicenter prospective study conducted by Canet et al., $5 \%$ of 2464 patients developed at least one PPC ${ }^{19}$. In addition, cardiac (39.6\%), thoracic (31.4\%) and abdominal surgeries $(7.2 \%)$ were the most complicated surgeries. Highest rates of 30th and 90th day postoperative mortalities and prolonged ventilation requirements were after abdominal surgeries and the length of hospital stay was directly proportional with the number of complications. A comprehensive analysis of the study findings revealed seven independent predictive risk factors for PPC as lower preoperative arterial oxygen saturation, acute airway infection in the preceding month, age, preoperative anemia, upper abdominal or thoracic surgery, surgery duration more than 2 hours and emergency cases ${ }^{19}$.

Besides a proper pain management, oxygen therapy and early mobilization, there are several additional strategies to prevent and treat atelectasis, postoperative hypoxemia and PPC. One of them is PEEP use during surgery. The medical literature consists of studies suggesting that the use of a $10 \mathrm{~cm} \mathrm{H}_{2} \mathrm{O}$ PEEP opens the collapsed alveoli ${ }^{20}$. Rusca et al. added $10 \mathrm{~cm} \mathrm{H}_{2} \mathrm{O}$ CPAP before induction and ensured insignificant atelectasis, even with 10 minutes long $100 \%$ oxygen use during induction ${ }^{21}$. Avoiding the use of high rates of oxygen before and during anesthesia and during recovery from anesthesia is another precaution to prevent atelectasis, because recruitment maneuver used in the management of atelectasis is ineffective in case where $100 \%$ oxygen is given for 10 minutes before extubation $^{22}$. Incentive spirometer and deep inspiration practice before and after surgery are also a way of preventing and treating peri-operative atelectasis. Thomas and McIntosh collected all studies about the effects of deep breath exercise, incentive spirometer and intermittent positive pressure breath on PPC, published from 1966 to 1992 in a meta-analysis ${ }^{23}$. They concluded that all these maneuvers reduced the PPC rate in study groups compared to control groups who were not treated with any of the maneuvers. All of these maneuvers are intended to increase lung volumes just as NIV; so why don't we use NIV for the same purpose?

The curiosity about the probable benefits of NIV gave rise to studies dealing with the prophylactic and curative use of NIV postoperatively and intraoperative$\mathrm{ly}^{14,24}$. Tobias was the first to publish postoperative use of $\mathrm{NIV}^{4}$. He treated acute postoperative respiratory failure associated with NIV in three children and three adults.

Postoperative hypoxemia and acute respiratory failure develop especially after thoracic and abdominal procedures. Although invasive mechanical ventilation is the mainstay of treatment for acute respiratory failure, some studies demonstrated relation between postoperative pulmonary mortality, and re-intubation and mechanical ventilation ${ }^{5}$. NIV provides all benefits of invasive mechanical ventilation and it reduces the risk of airway complications and nosocomial pneumonia at the same time. In addition, it reduces patient's discomfort and prevents airway resistance caused by the intubation tube, and helps to ensure better communication with the patient ${ }^{4}$. In this point of view, first precaution for the clinician is to prevent PPC; however, if it occurs unavoidably, the aim during management is to avoid re-intubation. NIV seems to fit for both purposes, thus is used for both prophylactically and curatively ${ }^{5}$.

Jaber et al. showed that NIV is a safe and well tolerated method in their study of 72 patients who had gastrointestinal surgery and respiratory failure 
postoperatively ${ }^{25}$. In this paper, we aimed to review the prophylactic use of NIV in postoperative periods of abdominal and thoracic surgeries.

\section{Methods}

We thoroughly searched Pubmed, Medline, and Cochrane Library beginning from 1979 January to 2014 June and limited the search within "clinical trials" and "randomized controlled trials". The search terms "thoracic surgery", "abdominal surgery", "thoraco-abdominal surgery" were combined with any of these: "non-invasive ventilation", "non-invasive positive pressure ventilation", "non-invasive respiratory support", "continuous positive airway pressure", "bilevel positive airway pressure". The studies dealing with just the preoperative or intra-operative NIV use, including pediatric patients, cardiac and bariatric surgeries, and in where NIV was applied as negative pressure ventilation or for curative purposes were excluded.

\section{Results}

Twelve studies consisting of a total of 858 patients met the inclusion criteria for final analysis ${ }^{26-35}$. Table 1 summarizes the included studies. Abdominal, thoracic and thoraco-abdominal surgeries were included in eight, two and two studies, respectively. NIV improved arterial blood gases in eight and spirometer data in four studies, and it decreased the rate of atelectasis in three studies.

\section{Abdominal Surgery}

Periodic NIV use immediately after extubation and continuing its use in postoperative period were associated with significantly higher oxygenation rates or faster recovery of lung volumes ${ }^{26,31,32}$. In a study conducted on 65 open laparoscopy operation patients, atelectasis rate was compared to respiratory therapy including incentive spirometer or coughing and deep breathing ${ }^{26}$.

PPC and re-intubation rate were similar when compared to conventional therapy, while arterial oxygenation was improved after NIV use ${ }^{27,28}$.

On the contrary, Carlsson et al. did not find any favorable effect of NIV on arterial oxygenation or spirometer measurements in comparison with the oxygen therapy ${ }^{29}$. In addition, analogously NIV did not lead a shorter hospital stay in 58 patients having abdominal surgery ${ }^{30}$.

Squadrone et al. used NIV for both prophylactic and curative purposes in the same study ${ }^{33}$. They included 209 patients and $1 \%$ of patients (one patient) required intubation in NIV group, while 10\% (ten patients) were re-intubated in the control group. The ICU stay and infection rate were significantly lower in NIV, however the length of hospital stay was not different.

\section{Thoracic Surgery}

Aqulio et al. investigated early effects of NIV after lung surgery in comparison with the conventional treatment. NIV improved arterial oxygenation after onehour application and this effect continued one more

Table 1. The summary of randomized controlled trials dealed with non-invasive ventilation

\begin{tabular}{|c|c|c|c|c|c|c|c|}
\hline Source & Surgery & $\mathrm{N}$ & Rate of Atelectasis & Spirometric Data & Arterial Blood Gas & Intubation rate & Outcome \\
\hline Stock et al. & Elective abdominal surgery & 65 & Favour NIV & Favour NIV & ND & ND & ND \\
\hline Anderes et al. & Elective abdominal surgery & 30 & ND & ND & Favour NIV & ND & ND \\
\hline Böhner et al. & Elective abdominal surgery & 204 & ND & ND & Favour NIV & Favour NIV & ND \\
\hline Carlsson et al. & Cholecystectomy & 24 & No difference & No difference & No difference & ND & ND \\
\hline Denehy et al. & Elective abdominal surgery & 58 & ND & No difference & No difference & ND & No difference \\
\hline Linder et al. & Elective abdominal surgery & 34 & ND & Favour NIV & ND & ND & ND \\
\hline Ricksten et al. & Elective abdominal surgery & 50 & Favour NIV & Favour NIV & Favour NIV & ND & ND \\
\hline Squadrone et al. & Elective abdominal surgery & 209 & ND & ND & Favour NIV & Favour NIV & No difference \\
\hline Aguilo et al. & Elective lung resection & 19 & ND & ND & Favour NIV & ND & ND \\
\hline Perrin et al. & Elective lobectomy & 39 & No difference & No difference & Favour NIV & ND & ND \\
\hline Fagevik et al. & Thoracoabdominal surgery & 70 & ND & No difference & Favour NIV & Favour NIV & No difference \\
\hline Kindgen-Milles et al. & Elective thoraco-abdominal aneurysms & 56 & Favour NIV & ND & Favour NIV & Favour NIV & ND \\
\hline
\end{tabular}


hour after the cessation of the ventilator support and carbon dioxide level and physiological dead space did not change at that moment. The procedure was feasibly tolerable and only one of the patients had considerable pleural air leak ${ }^{34}$.

Perrin et al. applied prophylactic NIV in both preoperative and postoperative periods of the same patients and compared it to oxygen therapy. They tested whether NIV ensures a better gas exchange and pulmonary function after lung resection in patients with a forced expiratory volume lower than $70 \%$ of predicted ${ }^{35}$. Gas exchange and spirometer values were better and hospital stay was lower in NIV group.

\section{Thoraco-abdominal Surgery}

The need for re-intubation and prolonged mechanical ventilation was significantly lower in prophylactic NIV group when compared with the control group in a study enrolling 70 patients in the postoperative period of resection for esophagus or cardia cancer; however gas exchange and lung volumes were similar in both groups ${ }^{36}$.

Kingden-Milles et al. compared prophylactic use of continuous and intermittent NIV after thoracoabdominal aortic aneurysm repair and revealed that oxygenation was better in continuous NIV group ${ }^{37}$. Hospital stay and rate of PPC were significantly lower in continuous NIV group.

\section{Discussion}

This paper reviews randomized controlled clinical trials about prophylactic NIV application in postoperative period of abdominal and thoracic surgery starting from 1979 to 2014 June, so it is the most extensive review in this sense.

PPC is still an important issue because it is a big burden on the physical and psychological health of patients besides its $\operatorname{costs}^{38}$. NIV is not an old technique to treat or prevent these complications; it has become popular since 1990s. Many reviews actually suggest that patients with higher risks for postoperative respiratory failure; including the individuals who are obese or affected by lung diseases and those undergoing surgical procedures at higher risk of PPC, and patients undergoing cardiac, thoracic or upper abdominal surgery; would benefit from NIV mostly ${ }^{38-40}$. The risk of PPC is highest in cardiac surgery, followed by thoracic and abdominal surgeries ${ }^{19}$. Başoğlu et al. reported \%9-69 risk of PPC occurrence after upper abdominal surgery, and the rate did not decrease despite improvements in anesthetics and surgical technologies through years ${ }^{41}$.

Hypoxia occurs in $30-50 \%$ of postoperative abdominal surgery patients, even after an uncomplicated surgery and anesthesia, and 8-10\% them need re-intubation and mechanical ventilation in the postoperative care unit ${ }^{5,18}$. NIV, particularly in prophylactic use, can be brilliant and miraculous. Besides, it is cheap, safe, practical and well-tolerated by the patients.

To be honest, the medical literature lacks studies recommending the routine prophylactic use of NIV in the postoperative periods of thoracic and abdominal operations. However, the results of currently performed studies seem to be mostly on NIV's favor. They show better findings of arterial blood gas and spirometer values, and atelectasis rate. Thus, NIV still has the chance for being within the recommendations of practice guidelines. However, we still do need more prospective studies with larger sample sizes in order to achieve stronger evidence to recommend NIV's routine use in the postoperative period.

In addition, atelectasis rate was dependent on the radiological findings in the previous studies and the clinical outcomes were not thoroughly evaluated. Thus, further prospective studies are needed to identify the true rate of atelectasis and its clinical implication.

Some clinicians have concerns about using NIV in gastrointestinal surgery and mostly they think that NIV may cause anastomosis leak. However, the literature lacks any serious complication resulted from NIV.

In conclusion, prophylactic NIV use after thoracic or abdominal surgery is still an untouched topic to be studied on. It seems that it has the potential for use in routine daily practice; however our hypothesis should be tested with more prospective clinical studies.

\section{References}

1. Özcan Ergin P, Noninvazif Ventilasyon. In: Dikmen Y, editör. Mekanik Ventilasyon, 1st ed. İstanbul: Güneş Kitabevleri; 2012:107-14.

2. Hillberg RE, Johnson DC. Noninvasive ventilation. New Engl J Med 1997;337:1746-52.

3. Rabatin JT, Gay PC. Noninvasive ventilation. Mayo Clin Proc 1999;74:817-20.

4. Tobias JD. Noninvasive ventilation using bilevel positive airway pressure to treat impending respiratory failure in the postanesthesia care unit. J Clin Anesth 2000;12:409-12.

5. Jaber S, Chanques G, Jung B. Postoperative noninvasive ventilation. Anesthesiology 2010;112:453-61. 
6. Cereda M, Neligan Patrick J, Reed Amy J. Noninvasive respiratory support in the perioperative period. Current Opinion in Anaesthesiology 2013;26:134-40.

7. Vignaux L, Vargas F, Roeseler J, et al. Patient-ventilator asynchrony during noninvasive ventilation for acute respiratory failure: A multicenter study. Intensive Care Med 2009;35:840-6.

8. Vignaux L, Tassaux D, Carteaux G, et al. Performance of noninvasive ventilation algorithms on ICU ventilators during pressure support: A clinical study. Intensive Care Med 2010;36:2053-9.

9. Certaux G, Lyazidi A, Cordoba-Izqierdo A, et al. Patient ventilator asynchrony during noninvasive ventilation: A bench and clinical study. Chest 2012;142:367-76.

10. Keenan SP, SinuffT, Burns KE, et al. Clinical practice guidelines for the use of noninvasive positive-pressure ventilation and noninvasive continuous positive airway pressure in the acute care setting. CMAJ 2011;183:195-214.

11. Rennotte MT, Baele P, Aubert G, et al. Nasal continuous positive airway pressure in the perioperative management of patients with obstructive sleep apnea submitted to surgery. Chest 1995; 107:367-74.

12. Adasenya AO, Lee W, Greilich NB, et al. perioperative management of obstructive sleep apnea. Chest 2010;138:1489-98.

13. Ferrer M, Esquinas A, Arancibia F, et al. Noninvasive ventilation during persistent weaning failure: a randomized controlled trial. Am J Respir Crit Care Med 2003;168:70-6.

14. Chiumello D, Chevallard G, Gregoretti C. Non-invasive ventilation in postoperative patients: A systematic review. Intensive Care Medicine 2011;37:918-29.

15. Gunnarsson L, Tokics L, Gustavsson H, et al. Influence of age on atelectasis formation and gas exchange impairment during general anaesthesia. Br J Anaesth 1991;66:423-32.

16. Özyilmaz E, Kaya A, Postoperatif hastada gelisen solunum yetmezliginde noninvazif mekanik ventilasyonun yeri. Available from: http://www.tuberktoraks.org/managete/fu_ folder/2012-02/html/2012-60-02-185-192.htm

17. Daley M. D, Norman P. H, Colmenares M. E, et al. Hypoxaemia in adults in the post-anaesthesia care unit. Canadian Journal of Anaesthesia 1991;38:740-6.

18. Nicholau D. The Postanesthesia Care Unit. In: Miller RD, editor. Miller's Anesthesia Volume 2, 7th ed. Philadelphia: Elsevier; 2010:2707-28.

19. Canet J, Gallart L, Gomar C, et al. Prediction of postoperative pulmonary complications in a population-based surgical cohort. Anesthesiology 2010;113:1338-50.

20. Hedenstierna G, Edmark L. The effects of anaesthesia and muscle paralysis on the respiratory system. Intenseive Care Med 2005;31:1327-35.

21. Rusca M, Proietti S, Schnyder P, et al. Prevention of atelectasis formation during induction of general anesthesia. Anesth Analg 2003;97:1835-9.

22. Benoit $\mathrm{Z}$, Wicky $S$, Fischer JF, et al. The effect of increased FiO2 before tracheal extubation on postoperative atelectasis. Anesth Analg 2002;95:1777-81.

23. Thomas JA, McIntosh JM. Are incentive spirometer, intermittent positive pressure breathing, and deep breathing exercises effective in the prevention of postoperative pulmonary complications after upper abdominal surgery? A systematic overview and meta-analysis. Phys Ther 1994n; 74:3-10.
24. Cabrini L, Plumari VP, Landoni G, et al. Intraoperative prophylactic and threpeutic non-invasive ventilation: a systematic review. British Journal of Anaesthesia 2014;112:638-47.

25. Jaber S, Delay J, Sebbane M, et al. Outcomes of patients with acute respiratory failure after abdominal surgery treated with noninvasive positive-pressure ventilation. Chest 2005;128:2688-95.

26. Stock M, Downs J, Gauer P, et al. Prevention of postoperative pulmonary complications with CPAP, incentive spirometer, and conservative therapy. Chest 1985;87:151-7.

27. Anderes C, Anderes U, Gasser D, et al. Postoperative spontaneous breathing with CPAP to normalize late postoperative oxygenation. Intensive Care Med 1979;5:15-21.

28. Bohner H, Kindgen-Milles D, Grust A, et al. Prophylactic nasal continuous positive airway pressure after major vascular surgery: results of a prospective randomized trial. Langenbecks Arch Surg 2002;387:21-6.

29. Carlsson C, Sonden B, Thylen U. Can postoperative continuous positive airway pressure (CPAP) prevent pulmonary complications after abdominal surgery? Intensive Care Med 1981;7:225-9.

30. Denehy L, Carroll S, Ntoumenopoulos G, et al. A randomized controlled trial comparing periodic mask CPAP with physiotherapy after abdominal surgery. Physiother Res Int 2001;6:236-50.

31. Lindner KH, Lotz P, Ahnefeld FW. Continuous positive airway pressure effect on functional residual capacity, vital capacity and its subdivisions. Chest 1987;92:66-70.

32. Ricksten SE, Bengtsson A, Soderberg C, et al. Effects of periodic positive airway pressure by mask on postoperative pulmonary function. Chest 1986;89:774-81.

33. Squadrone V, Coha M, Cerutti E, et al. Continuous positive airway pressure for treatment of postoperative hypoxemia: A randomized controlled trial. JAMA 2005;293:589-95.

34. Aguilo R, Togores B, Pons S, et al. Noninvasive ventilatory support after lung resectional surgery. Chest 1997;112:117-21.

35. Perrin C, Jullien V, Vénissac N, et al. Prophylactic use of noninvasive ventilation in patients undergoing lung resectional surgery. Respir Med 2007;101:1572-8.

36. Fagevik Olsen M, Wennberg E, Johnsson E, et al. Randomized Clinical study of prevention of pulmonary complications after thoraco-abdominal resection by two different breathing techniques. Br J Surg 2002;89:1228-34.

37. Kingden-Milles D, Muller E, Buhl R, et al. Nasal-continious airway pressure reduces pulmonary morbidity and length of hospital stay following thoraco-abdominal aortic surgery. Chest 2005;28:821-8.

38. Shander A, Fleisher LA, Barie PS, et al. Clinical and economical burden of postoperative pulmonary complications: patient safety summit on definition, risk reducing interventions, and preventative strategies. Crit Care Med 2011;39:216-72.

39. Eichenberger A, Prilotti S, Wicky S, et al. Morbid obesity ad postoperative pulmonary atelectasis: an underestimated problem. Anesth Analg 1999;95:1788-92.

40. Xue FS, Li BW, Zhang GS, et al. The influence of surgical sites on early postoperative hypoxemia in adults undergoing elective surgery. Anesth Analg 1999;88:3-19.

41. Başoğlu O, Bacakoğlu F, Ersin S, et al. Üst karin cerrahisinde postoperatif solunumsal komplikasyon riskinin preoperative parametrelerle iliskisi. Toraks Dergisi 2000;2:17-22. 